Wohlwend, K. E. (2016). Who gets to play? Access, popular media and participatory literacies. Early Years: An international research journal, 37(1), 62-76.

doi:10.108o/09575146.2016.121969

\title{
Who Gets to Play? Access, Popular Media, and Participatory Literacies
}

\author{
Karen E. Wohlwend
}

Indiana University, Bloomington

\begin{abstract}
:
To be relevant to modern childhoods immersed in media cultures, we need to think beyond print-intensive reading/writing workshops and to support play-enriched participatory literacies. Participatory literacies are ways of interpreting, making, sharing, and belonging in increasingly globally- and digitally-mediated cultures. Early literacy is too often over-simplified as a set of cognitive and "constrained skills" for beginning reading: easily measured tasks "such as learning the letters of the alphabet, [that] are constrained to small sets of knowledge that are mastered in relatively brief periods of development" (Paris 2005, 185). This approach overlooks the ways that children play their way into cultures, using play as a key participatory and "printless" literacy that accesses popular media as rich literary repertoires of characters and storylines. When opportunities to play in school vanish, or are limited by a well-intentioned commercialfree bias, children lose the chance to tap into their passions for and knowledges of popular media as powerful literacy resources and cultural capital in peer cultures. The article examines how children's play shows what they know and reveals their participatory literacies in preschool classrooms where teachers provide play-based media literacy curricula. Data are excerpted from a five-year study of literacy play in classrooms that provide a space for children to draw upon popular media repertoires as cultural capital and resources for literacy development. Mediated discourse analysis of classroom video located and analyzed children's play for use of creative and collaborative dimensions of participatory literacies. Results showed that young children drew on their media knowledge during play to fluidly improvise dialogue and story action in ways that enriched and sustained play themes and friendships over time but also allowed isolated children to gain access to play groups.
\end{abstract}


To keep up with expanding literacies in rapidly-changing globalized socioeconomic worlds (Sefton-Green et al. 2016), we need relevant curricula that develops the literacy practices that young children use in everyday life. This means thinking beyond print-intensive reading/writing workshops to envision playful and digital early childhood curricula that support participatory literacies in converging media-popular media, digital media, social media--that make up modern cultural repertoires for communicating and living. Participatory literacies are ways of interpreting, making, sharing, and belonging in increasingly globally- and digitally-mediated cultures across multiple media platforms. For example, in transmedia storytelling (Jenkins et al. 2006), characters and narratives move across films, television, books, blogs, video games, toys, food, and consumer goods. To examine how children engage powerful and dense media imaginaries (Wohlwend and Medina 2014) to mediate their classroom peer cultures, this article focuses on pretend play with popular media, rather than on exploratory play with sensory materials or physical play at recess. For young children, play is a key participatory literacy that moves across multimedia platforms, commercial sites, and toy franchises, that enables access to popular media as rich literary repertoires of characters, genres, and story ideas.

Unfortunately in U.S. early childhood classrooms, literacy curricula is too often over-simplified as a set of cognitive and "constrained skills" for beginning reading: easily measured tasks "such as learning the letters of the alphabet, [that] are constrained to small sets of knowledge that are mastered in relatively brief periods of development" (Paris 2005, 185). When a print-centric emphasis on constrained skills combines with an all-work-and-no-play approach, the result is a narrow curriculum that limits the ways children can play their way into literacy learning and childhood cultures. Reduced play opportunities in the early years classroom distance children from important literacy resources (Dyson 2006) and their cultural funds of knowledge (Moll et al. 1992). When opportunities to play in school vanish, or are limited by a well-intentioned commercialfree ban, children lose the chance to tap into their community experiences, family interests, and cultural expertise as familiar literacy resources.

When play leaves the classroom, it also takes with it an important cohesive element for building peer cultures and friendships (Corsaro 2003). My previous research has shown that as children pretend together, they mediate their social histories and shared norms for belonging, using commercial media toys and child-made artifacts to pivot (Vygotsky 1935/1976) among play worlds and classroom cultures to access more powerful identities and practices (Wohlwend 2011). This has substantial impact for children on the fringes of peer cultures, who can trade upon the cultural capital of trendy popular media to gain access to play groups. Popular media expertise can mitigate a child's outsider social status, which negatively affects academic achievement and classroom participation in incorrigible cycles of exclusion (McDermott 1985; Mehan 1979; Christian and Bloome 2004). Thus, who gets to play becomes an issue of social justice 
when some children are denied an important pathway to increased participation in school and peer cultures.

In this article, I examine how children who played alone were able to gain access to play groups and to create play texts with peers through their use of popular media, digital media, and participatory literacies, to answer the research questions:

- Who gets to play? How do children get access to play groups?

- Which practices seem routine (natural, expected) and necessary for participation in this playgroup?

- How are artifacts used for making and remakings of imagined and immediate identities for toys and players (e.g., characters, player roles, cooperating friends)?

The research in this article is excerpted from a five-year ethnographic study on literacy playshops (Wohlwend 2013), teacher-created media literacy curricula designed to provide a space for young children to produce digital videos by playing with popular media themes and toys, using new technologies and popular media repertoires as cultural capital and resources for literacy development. The term playshop intentionally twists the more familiar workshop. Playshop reverses the top-down modeling in teacher-led apprenticeships and print-oriented tasks of reading/writing workshop. Playshops complement workshops by privileging learner-led media-rich play as sources of child expertise and cultural resources. In literacy playshop research studies, young children played and collaborated to make films using themes they chose, including popular media themes and toys from their favorite media passions) to record their own stories with iPads or digital Flip cameras. They also used digital animation apps on iPads to make puppet shows with avatars they created from digital photographs of friends, media characters, or favorite classroom toys. In this article, close analysis of excerpts of video data from two of preschool playshops reveals a space where children with few friends could access their popular media knowledge as literacy resources, explore digital storytelling, and participate more fully in peer play groups. In the first preschool, teachers decided to reverse their "commercial-free" stance that banned popular media toys and to bring in Disney Princess dolls as part of a filmmaking center. In the second classroom, teachers provided iPads so children could make digital films with their own toys. Mediated discourse analysis (MDA) of classroom video located and analyzed children's play for moments of creative and collaborative participatory literacies. Results showed that young children who typically did not join in group play drew on their media passions during play to fluidly improvise dialogue and story actions in ways that sustained colloborative pretense and entertained peers but also allowed isolated children gain access to play groups. 


\section{Background}

\section{Playing with multiple media in preschool}

Play is a longtime staple of early childhood education, widely recognized as a developmentally appropriate (Bredekamp and Copple, 1997) approach to learning that allows children to pretend their understandings of the world around them (Göncü 1998). Early literacy educators have used play to drive inquiry (Dewey 1915/200o), inspire storytelling (Paley 2004) enrich writing (Dyson 2003; Ray and Glover 2008), and infuse literacy curricula with children's funds of knowledge (Moll and Gonzalez 1992). In recent decades, dramatic play opportunities allowed children to access their cultural expertise with language, literacies, knowledge, and social practices gained through everyday living (e.g., Gregory, Long and Volk 200o). But after decades of accountability, standardization, pushed-down curricula, and high stakes testing in U.S. public schools, mandated by successive waves of reformist legislation at the federal and state levels, play is dwindling (Dyson and Genishi, 2014). Even in the formerly safe haven of preschool, a growing pressure to achieve is "crushing" children (Christakis 2016).

Moreover, an all-work-and-no-play approach to early learning is much more likely to be enforced in schools in high poverty locations where children are already marginalized, in comparison to wealthier suburban or progressive private schools that provide learner-led constructivist interest-driven curriculum in which play is viewed as a necessary tool for early learning development (Colegrove and Adair, 2014). Making time for play may seem risky in watch-list schools under state scrutiny where teachers are assessed on their implementation of scripted curricula (Allington and Pearson, 2011). In this way, play is becoming a perquisite of affluence, a privilege for those who can afford to attend schools that enjoy the freedom to adopt creative and innovative curriculum.

However, it is also important not to romanticize play (Sutton-Smith1997; Roskos and Christie 2001; Grieshaber \& McArdle, 2010) but to also address its problematic aspects. Young children wield play as a social practice for their own purposes, making and enforcing cultural boundaries in ways that can hurt, bully, and exclude, or otherwise make adults uncomfortable (Boldt, 1996;; Grace \& Tobin, 1997; Thiel, 2014; Wohlwend, 2007, 2012). For example, the friendship-building potential of play can be a vehicle for both inclusion and exclusion, creating insiders and outsiders in play groups and children's peer cultures (Corsaro 2003). Additionally, affinity groups (Gee, 1996) form around play materials (e.,g., media dolls and action figures), valued as cultural capital by local peer cultures (Fernie, Madrid and Kantor 2011) creating entry vehicles that help children gain access to peer groups. Finally, children's media toys are objects of affection and infection, satisfying emotional attachments and spreading mass media stereotypes (Jones et al. 2012) often with substantial impact on children's social worlds. (Pugh 2009).

School policies and teacher attitudes toward media themes and toys can produce disparity when some kinds of play are discouraged at school while others are encouraged, 
privileging those players who are most familiar with school-preferred toys, which are often natural or generic materials rather than commercial action figures, trading cards, or video games that have significant appeal in peer cultures. Teacher preferences often reflect middle-class tastes and nostalgia for more agrarian times that disdain mass-market products and advanced technologies (Marsh and Millard 2006). When access to media toys is limited, low-income children are most likely to be disadvantaged by middle-class taste (Pompe 1996; Seiter 1993) when class distinctions are materialized through commercial-free bias toward generic toys. In some programs, prohibitions on popular media aim to protect children from overly violent or sexual media themes in pervasive media. For example, teachers may shut down play that seems too risky for school, deemed overly sexual or violent (Thiel 2014). At other times, teachers choose to bring in popular media as inducements for literacy tasks, such as writing or drawing. When opportunities to play in school are limited by a well-intentioned ban on perceived inappropriate themes (Thiel 2014) or are removed altogether, some children lose the chance to tap into their knowledge of popular media as literacy resources and cultural capital in peer cultures (Pugh 2009; Dyson 2003).

Finally, play in the twenty-first century is often intertwined with digital technologies, giving it renewed relevance as a participatory literacy that allows children to explore the core digital literacy practices and ways of belonging on social networks where we produce, collaborate, and share multimedia with family, friends, and followers.

\section{Literacy Playshop Curriculum}

In this study, early childhood teachers in practitioner inquiry study groups worked with researchers to develop digital literacy and play-based media literacy playshop curriculum. Literacy playshops are situated, unique to each setting, and learners' interests inform teacher mediation at three levels: learner explorations, material mediators, and teacherguided engagements.

- Learner Explorations: The largest, most frequent blocks of time are devoted to learner explorations, recognizing that children bring media and technology knowledge and passion into their play (Wohlwend 2009b). These open-ended explorations enable children to explore bits of song lyrics and movie dialogue or try out a sound effect on an iPad, leading to new discoveries, proliferating the pathways into literacy by providing a risk-free learning environment and encouraging a broader range of participation. Through playwatching, teachers look for opportunities to extend and respond to children's current media understandings and literacy practices by ensuring that children have access to material mediators that emerge during explorations.

- Material Mediators: Materials accrue shared meanings through their histories of use so that a doll or toy anchors a set of meanings that authorize an expected character, media narrative, and a role for its player. Mediators such as books, cameras, or toys anchor children's negotiated rules for the who's-being-what in pretend scenarios as well as turn-taking or equipment handling. Mediators save meanings in some way (via 
cameras, pencils, iPads) or make meanings easier to communicate or understand (via storyboards, subtitles, narration). Teachers also mediate when they join in as coplayers to support play frames in character to clarify play or to help children resolve a conflict.

- Teacher-Guided Engagements: Occasionally, teachers gather children to share a discovery or demonstrate new literacies or technologies. These whole class activities also allowed teachers to quickly provide children with enough experience in storytelling, collaboration, or equipment handling to work in independently or small groups with peer support.

These three levels of mediation intersect with four overlapping sets of practices for meaning-making and participation:

- Play is a "printless" literacy that creates action texts (Wohlwend 2011), stories enacted with bodies, toys, props, and scenery rather than written with print on paper. Players cooperate and agree to a set of pretend scenarios or "as if" worlds that can change the immediate real classroom into a castle, spaceship, or car. Play produces a pretend context that helps emergent literacy users learn how, where, when, and why to use particular ways of communicating printless texts. All these components must be closely examined and reinterpreted to fit the emergent understandings, strengths, and needs of early childhood learners and this work is ongoing (Vasquez and Felderman 2012; Wohlwend 2013).

- Collaboration enables the emergent meanings in multi-player pretense, live-action dramas, or films that are constantly subject to the next players' action that triggers renegotiation of the pretended meaning under construction. In playshops, collaborative structures provide opportunities for seeing others' perspectives and to develop the shared decision-making needed to pool ideas and create a shared story.

- Storying turns players' attention to literary structures such as character, plot, setting, and theme. Films have their own conventions such as ways of framing shots that create genre features in film genres. The term storying rather than storytelling focuses on the multiple modes in digital filmmaking and embodied drama.

- Media Production: Digital technologies for media production have become highly child-friendly, with phones that are just the right size for small fingers, and apps with minimal print that can be operated primarily through with icons. Important for play, these advancements enable much more student autonomy and peer collaboration, far different from the first study of a kindergarten playshop (Wohlwend 2011) where Sony Handycams were only occasionally handled by children, and required the presence of a hovering adult to assist with operation and any accidents. Flip cams (unfortunately now discontinued) were an affordable and sturdy option that allowed children to create films independently. In preschools, teachers' phones are most common tool for capturing student play but teachers are understandably reluctant to hand over their personal phones to children (Wartella et al. 2013). However, with recent one-to-one iPad initiatives in PK-12 education, classrooms are increasingly equipped with some hand-held technology. 


\section{Theoretical framework: Play, peer cultures, and popular media}

\section{Play and peer cultures}

Children play their way into cultures, pretending to be "a head taller" (Vygotsky 1935) while approximating the everyday practices that they see adults doing. Play is participatory literacy: a social practice for making communicating meanings and for learning and joining in cultural practices (Sutton-Smith 1997; Göncü 1998). Important to issues of equitable participation, play has transformative power to reframe contexts (Bateson 1956; Goffman 1974) changing a confining reality into an alternative, malleable imaginary (Medina and Wohwlend 2014) or "as if" world (Holland et al. 1998) where identities and relationships can be reshaped. These transformations have particular importance in the peer cultures that children produce themselves in response to surrounding adult expectations.

...Children are always participating in and are part of two culturestheir own and adults' - and these cultures are intricately interwoven...

Further, children interpret-and contribute to-adult culture through their collective actions in the peer cultures they create throughout their childhoods. I define children's peer cultures as the stable sets of routines, artifacts, values, and concerns that children produce and share with each other. (Corsaro 2012, 489)

In the twenty-first century, play happens in spaces where the lines between global and local, material and immaterial, online and offline space, and bodies and tools are already blurred (Marsh 2014; Burnett, Merchant, Pahl and Rowsell 2014). The fluid nature of this convergence is captured by the metaphor of flickering (Fleer 2014) to characterize the small mercurial moves young children make between collective and individual imagined spaces, in and out of imaginary scenarios in physical realities and virtual representations with digital technologies. For example, during play fighting children navigate pretend and actual bodies and individual and collective actions as they remain physically aware of concrete consequences while pretending an imagined fight (Fleer 2014).

\section{Permeable playshops and popular media}

"...If teachers take play seriously, that is, as a way to learn more about children and their literacies, they may come to treat it as a valuable resource for child and teacher learning" (Kontovourki and Siegel 2009, 37). What appears to teachers as a conflict between peer culture passion for popular media and school culture concerns for appropriate content can be a productive opportunity for innovative practices and pedagogies (Galbraith 2011; Fernie, Madrid and Kantor 2011). 
Permeable curriculum (Dyson 1993) describes pedagogy that is open to children's cultures, interests, and desires, where curriculum is negotiated with children, rather than done to them. In early childhood classrooms with a literacy curriculum permeable to media, children draw upon media in to carry out literacy practices in school cultures but also to belong in peer cultures (Dyson 2003; Wohlwend 2011). Teachers can use permeable curriculum to work with, rather than against, peer cultures. For example, Galbraith (2011) found that when teachers reversed their opposition to superhero play and instead offered responsive mediation, children invented new superhero narratives that allowed more players to join in and honored one another's contributions in ways that strengthened children's friendships. Similarly, my playshop studies show that thoughtful teacher mediation that considered children's expertise and motives in media play enabled more inclusion for multilingual players (Wohlwend 2011, 2015) and supported children's revision of gender stereotypes in media narratives (Wohlwend 2009a, 2012).

\section{Methods: Studying participatory literacies through media discourse analysis}

\section{Research context: Two preschool playshops}

The classroom examples in this article are excerpted from a five-year study of young children's play literacies in preschool through first grade classrooms where teachers developed and implemented literacy playshop curriculum using popular media and digital filmmaking. This article focuses on two preschool classrooms (each classroom had two lead teachers and about 20 three- to five-year-old children) in university childcare centers serving families of faculty, graduate students, and community members in a small town in the US Midwest. We visited each classroom during two-hour play sessions, one to two days per week for one academic year. It is important to note that our research focus required classrooms that provided learner-led play and this led us to the university preschools, privileged spaces with progressive curricula where teachers have the flexibility to follow learners' interests. By contrast, local childcare centers and preschools reduced time for play or offered teacher-structured activities to meet academic goals.

The childcare centers provided an emergent play-based, learner-led curriculum. Based on observed children's interests, teachers added materials for exploratory and playful activities in open-ended learning centers: a house with wooden kitchen furniture, dress-up costumes, and baby dolls; large and small blocks; reading corner with books, pillows, and sofas; sensory tables for water, sand, etc.; an art table for painting, printing, playdough sculpting; a science table with insect specimens, a wooden dollhouse and other miniature playsets, baskets of trains and cars). Daily schedules included several large blocks of play as children moved freely from center to center around the room. 


\section{Mediated discourse analysis}

(Scollon 2001; Scollon and Scollon 2004) makes expected ways of belonging visible and identifies how participation in school and peer cultures is mediated through artifacts such as media toys and digital technologies. MDA of children's physical actions with toys and iPads within play events looked closely at turn-taking and toy handling to identify practices of belonging.

During classroom visits, three or more cameras captured children's dramatic play, storying, and filmmaking activities, including a long view of classroom to capture children's movement in and out of groups and cameras placed at two play centers to enable close analysis of children's interactions with materials and one another. Data sources included child-produced films, classroom play, and filmmaking activity.

The focus in MDA on materials and activity, rather than on spoken language, guided close analysis of video-recorded actions and inspected the multimodal meanings embedded in bodies, toys, and tools. The two classrooms were selected to contrast teachers' opposing approaches to popular media toys; one class banned popular media toys at school while the other allowed children to play with toys from home as they wished. Video analysis software (i.e., StudioCode) facilitated examination of situated activity in each play center location in both classrooms, how frequently groups chose to play together, and groups' choice of play themes and materials. A four step filtering process in MDA located

1) classroom locations and their persistent play groups and materials

2) within these locations, intersections of key play practices (i.e., play, collaboration, storying, media production)

3) within these nexus, transformational moments where children used toys and digital tools to make and remake shared meanings that they co-constructed together and that also substantially changed their social participation in the playgroup (e.g., where isolated children joined a group and took on a leadership role).

4) within these instances, micro-interactional analysis (i.e., tracking meaning negotiation and social conflict where children's play sustained and challenged ways of belonging) identified instance sequences that show how children wielded toys and media knowledge as literacy resources and social organizing tools. In the following section, I share an instance from a transformational moment from each classroom and two highly popular media franchises: Disney Princesses and The Avengers. Pseudonyms are used for all participants. 


\section{Findings: Media and technologies come to preschool}

\section{Bringing popular media toys into a commercial-free playshop}

In the first childcare center, rules governed how many and how often children could bring their "home" toys to school, to discourage children from "showing off" displays of wealth that might highlight disparate socioeconomic status. The preschool teachers actively worked against inequitable displays in the classroom by limiting the number of toys children could bring for sharing time. Teachers also wanted to be sensitive to the wishes of families who tried to maintain a "commercial-free" atmosphere by limiting children's contact with popular culture or mass media. They also hoped to prevent lost or broken possessions or conflicts over coveted toys. However, after reading research by Jackie Marsh and Vivian Vasquez in our study group sessions, the teachers conducted a popular culture audit to tally the popular media characters that decorated children's backpacks, clothing, and school supplies. The audit showed that children were interested in Transformers, Star Wars, and Disney Princess media, but the teachers felt that parents would find these popular media toys too violent or gendered. Instead, they decided on an approach they viewed as a compromise: They would provide a set of popular media toys but from a film they thought parents would find innocuous: Toy Story 3. However, because children had no connection to the film, they lost interest in the filmmaking materials after the first day (Medina and Wohlwend 2014).

Following this experience, two preschool teachers decided to provide Disney Princess dolls in the filmmaking center. They decided to bring in eight dolls and to provide these themselves to ensure that all children would have equal access, whether or not a child personally owned a princess doll.

On the first day that the princess dolls came to school, twelve girls in the class crowded around the filmmaking center table, holding and stroking hair and gowns of the Barbie-sized dolls. Grace picked up Ariel, the Little Mermaid, and began a conversation with one of the teachers.

Grace: ... I'm gonna bring my doll.

Teacher: Your doll? What is your doll?

Grace: My doll is... I'm gonna bring Sleeping Beauty. Her have a skirt. I'm gonna bring her. [twirling doll in her hands as she speaks].

Teacher: You're gonna share her?

Grace: Yeah.

Teacher: On Monday? 
Grace: Yeah.... [head down, looking at doll] I think I'm gonna take her. I want you to go to my house.

Teacher: You want me to go to your house?

Grace: You need to, you need, you didn't see my room.

Teacher: I haven't seen your room yet. You're right.

Grace: On [Monday], you might go to my house.

Teacher: Maybe you can take pictures and show us pictures.

Grace: Ok. I'm gonna take the whole class there!

Teacher: Oh, wow. The whole class

Grace's desire to bring her doll to school was framed by her teacher as an opportunity to bring the doll not as a toy for play but as an object for Sharing Time, an oral language development activity. A common practice in early childhood classrooms, daily show-and-tell sessions give children a chance to bring their possessions from home to "share," that is, to stand in front of the class, show a featured object, and talk about it. The practice of "sharing" - or more accurately showing - toys to other preschoolers was valued as an important way of belonging: aligning with school culture and teachers' goals of modeling language and eliciting children's verbal expression and with peer culture goals as a means to interest and engage friends through attractive toys. On another level, sharing time is an identity-building site where teachers shape children's narratives to fit school norms (Gee 1996) or verbal expectations for displays of appropriate femininities (Kamler 1999). In this classroom, teachers sought to downplay displays of material wealth by encouraging children to bring natural materials. However, children seemed much more eager to share beloved toys that also elicited enthusiastic response from peers.

In this classroom, social benefits sometimes extended beyond the official class sharing time when children's talk about toys evolved into invitations to their homes so friends could see and play with these toys. In Grace's case, her excitement and conversation about the princess dolls opened an immediate avenue for more social participation by playing with the other girls in this playgroup, something Grace seldom chose to do and a matter of concern to the teachers.

A few minutes later, Grace used her media knowledge of princess names to negotiate a complex moment of play among a small group of girls.

Grace [holding the mermaid doll and in-character as Ariel]: And I'm Ariel 
Allison [holding Sleeping Beauty doll, in-character as new character]: And mine is Minishawn [a name she's invented]

Grace [picking up a second doll, Snow White and stepping out of character to reject Allison's invented name and substitute an authorized commercial princess name]: No, her name is Cinderella.

Melanie [as player holding Cinderella doll, objects]: My name is Cinderella!

Allison [as player holding Sleeping Beauty doll, accepts doll's commercial name]: This is Sleeping Beauty!

Grace: [higher pitch signals she is stepping back into character as Snow White; affirms Allison's claim] "And this is my friend Sleeping Beauty. Hello!"

[Allison accepting Grace's play bid to restart play, responds to Snow White's introduction, and silently bounces Sleeping Beauty across the tabletop to meet Grace's Snow White doll.]

Grace [In character as Ariel]: "And this is your friend Snow White."

By including Allison and reinstating the commercial names of all the dolls, Grace adeptly resolved the conflict, while in character and animating two dolls. While working to uphold the "real" or authorized names of characters in the media narratives she knew, she moved fluidly in and out of play in flickers of collaboration with other players as they agreed upon character names, in quick renegotiations that allowed children to work through their conflicting ideas. These negotiations let children demonstrate their media knowledge and their fan affiliation as they challenged and upheld the proper names of the princess characters. In this short excerpt, Grace transformed from an isolated child to a storyteller and play leader by bringing all players back into the scenario and moving the play forward. For Grace, this moment of collaboration with other girls was transformative, mediating both the emergent story in the play narrative and the friendship norms in peer culture that allowed her to participate more actively.

In revising media narratives, children considered the authorized storylines but also players' desires, friendship bonds, and play goals. Players stepped in and out of pretense in their revisions of commercial narratives and character relationships in order to make room for meaningful roles for friends or to draw upon their shared understandings of filmic worlds and routines of family living. In one playgroup, girls turned the Belle princess doll into Sleeping Beauty's mother, merging the two fairytales but also changing a fantasy narrative into a sociodramatic family story. Across classrooms children played the stories they knew best, drawing upon scenes and scripts from family life for collaborative play. In preschool, the typically brief stories involved lots of physical 
movement of toys, simple greetings and labeling, and extended physical manipulation and exploration of the dolls, dresses, and materials.

\section{Bringing digital technologies into a media-permeable playshop}

In the second childcare center in this article, teachers took a different tack. Center policy already allowed children to bring and play with their own media toys in the classroom and the teachers frequently used their cell phones as a means of capturing children's play for sharing with parents. However, there was little digital technology available for children to use. During teacher study groups, the teachers in this center became interested in seeing what children would create when given opportunities to play with iPads and record their own movies.

In this classroom, children typically played in fairly stable groups of two or three, mostly with friends of the same gender. Play themes reflected children's friendships and their desire to play together as well as their friendship bonds, shared cultural knowledge, and popular media interests. For example, two play groups of boys chose to wear superhero capes as they jumped from climbing structures or raced miniature cars while playing media themes such as DC Comic's Batman or Marvel's The Avengers. In these groups, similar media interests supported group cohesion and shared play histories as children played together day after day and developed a set of shared expectations and pretend meanings. However, these bonding elements also created insiders and outsiders in patterns of inclusion and exclusion that became routine.

The largest playgroup consisted of six girls who regularly played family scenarios in the house, sometimes as princesses or fairies, supported by glittery tiaras, gauzy wings, or shiny long gown costumes. Another pair of girls played and replayed chase scenes from Disney's Frozen, repeatedly circling the room and calling out to one another as Anna and Elsa. The Frozen media franchise emerged as a unifying element with widespread interest that crossed gender and spanned playgroups. The attraction to the media franchise was almost universal: upon noticing the first snow of the season falling outside the large picture window, a child burst into the film's iconic song "Let It Go", and children around the room dropped what they were doing to join in.

Except Jonah. Jonah played on, alone and intent on a set of miniature cars. Despite teachers' attempts to interest him in group activity, he usually played by himself, with blocks, miniature playsets, or art materials, outside established friendship groups. Like Grace, a rare moment of connection with peers occurred when Jonah brought his own Transformers to school and other children crowded around him for a chance to handle and play with the toys.

However, Jonah's pattern of solitary play changed when the digital filmmaking station was introduced early in the second semester. From the first day, Jonah could almost always be found with an iPad, regularly making films with another child or two. 
In part, this was determined by rules at the filmmaking table. Due to the limited number of tablets (two) and to encourage collaboration, children were expected to share iPads with other children who arrived at the table and wanted to play. Each iPad was loaded with a wordless puppetry app (i.e., PuppetPals) that allowed children to record short cartoons with cutout characters that were animated by finger touches: tapping, dragging, squeezing, or stretching each character's image. The result was multiplayer filmmaking with many hands needed to operate the cutout characters on the touchscreen.

At the filmmaking table, Jonah sits next to Jenna who is intently cutting out an avatar on the iPad's touchscreen by tracing a finger around a photograph of Thor, a superhero in the Avengers franchise. Across the table, Evelyn bends over the second iPad, scrolling through a page of Google images of another Avenger, Ironman.

Jonah walks around the table to watch Jenna move through the page of images and soon asks if he can choose Ironman. Evelyn positions the iPad so he can see the screen. He scrolls and taps an image to select and enlarge the thumbnail of the photo. In the process, he navigates away from the image page. Evelyn reaches over and presses the home button, reopens the browser, and taps the back arrow to return to the image page. Heads together, the two children repeat this scrolling and selection process over and over, talking and tapping for almost five minutes as they decide together upon an Ironman photo to use for a cutout puppet.

This instance is packed with the digital literacies necessary for reading and navigating a screen of images (e.g., selecting apps, moving back and forth between screens, scrolling up and down a page, opening and closing apps). Additionally, the children shared materials, took turns, and reached agreement to choose a single image. But this is not to say that the transition from solitary to collaborative play was easy. Children were used to handling phones as individuals and initially resisted others attempts to reach in and play along on the touchscreen. For example, when others wanted to animate a digital puppet on the iPad, Jonah had brushed their hands away, tugging on the iPad, or moving it out of their reach. But with adult reminders over the course of several sessions, Jonah as well as the other players learned to cooperate on the small touchscreens, simultaneously advising one another, moving and animating puppet avatars, and voicing characters.

Overall, Jonah created the largest number of films, and children became interested in watching him create fast-moving animations with sound effects and expressive voices. The dialogue was almost unintelligible but this did not seem to diminish children's enjoyment of the films. A routine activity for several children was to begin playshop sessions by watching a few films created earlier by Jonah and saved on the index page of the app. The appeal of these brief videos puzzled adults, as the videos seemed to lack storylines, often featuring a moving jumble of character cutouts, bursts of unintelligible speech, squeals, and sound effects. But children found the films entertaining, chuckling at 
the sound effects and size distortions he created with photo cutouts of characters from Frozen and the Avengers, as well as photos of classroom toys such as small plastic zoo animals or dinosaurs. And this is key: Insider humor, shared among children in peer culture that mystifies adults, is a hallmark of peer culture and an important cohesive element that distinguishes children's play cultures from the adult world (Corsaro 2003; Fernie, Kantor and Madrid, 2011; Willett et al. 2013; Grace and Tobin 1997).

\section{Conclusion}

These preschool media play examples show the flickering transformations in storying and participation that are inherent in participatory literacies. Throughout the projects, when children had opportunities to use their media knowledge, they transformed their participation, their play narratives, and themselves, if only for moments. Timely teacher mediation can fan these promising sparks, providing time and materials that allow children to replay favorite themes and develop patterns of participation through repetition.

During play, filmmaking, making, and digital technology explorations in the playshop classrooms, we saw similar examples of children who transformed their social and academic participation from quiet onlookers or reluctant writers when teachers implemented media-permeable curriculum in the playshop classrooms in the study, most dramatic for isolated children like Grace and Jonah. Opportunities to play, rather than write, draw, or tell, a story made the difference, by providing an opening that allowed more children to not only participate but to lead in literacy play events, through embodied modes that were familiar and comfortable such as dramatic enactments or animated doll play where they held considerable expertise (Medina and Wohlwend 2014).

More educational research and programming is needed on early childhood media literacy. In the United States, media literacy is still remarkably understudied and rarely acknowledged as a literacy in K12 education, despite the pervasive influence of media in daily living (Hobbs and Jensen 2009). Even in Europe and Canada where media literacy education is a well-established discipline, significant tensions remain around issues of youth access, protection, and empowerment (Sefton-Green et al., 2016). The examples of very young children's media play in this article illustrate the need for research that acknowledges "the role of play, identity, voice and subjectivity in the practices of consuming and creating media"(Hobbs 2016, 7). The recognition that play with popular media and new technologies is a participatory literacy, both agentic and fraught with power relations, means approaches to research and teaching should consider both children's purposes as well as issues of equity (Marsh 2014; Vasquez and Felderman, 2014). The cultural production and transformation shown here suggests the value of sustained play opportunities in preschool classrooms where teachers can respond. It also points to the need for teacher education that prepares teachers to mediate popular media and peer culture in ways that develop critical awareness, participatory literacies, and inclusivity. 


\section{References}

Allington, Richard, and P. David Pearson. 2011. "The Casualities of Policy on Early Literacy Development." Language Arts 89 (1):70-74.

Bateson, Gregory. 1956. "The Message is 'This is Play”" in Group Processes: Transactions of the Second Conference, 1955. Edited by Bertram Schaffner, MD, 145-242.

Boldt, G. M. (1996). Sexist and heterosexist responses to gender bending in an elementary classroom. Curriculum Inquiry, 26(2), 113-131.

Bredekamp, Sue, and Carol Copple, eds. 1997. Developmentally Appropriate Practice in Early Childhood Programs. Washington, DC: National Association for the Education of Young Children.

Burnett, Cathy, Guy Merchant, Kate Pahl, and Jennifer Rowsell. 2014. "The (Im)Materiality of Literacy: The Significance of Subjectivity to New Literacies Research." Discourse: Studies in the Cultural Politics of Education 35 (1):90-103.

Christakis, Erika. 2016. "The New Preschool is Crushing Kids." The Atlantic (January/February).

Christian, Beth, and David Bloome. 2004. "Learning to Read is Who You Are." Reading and Writing Quarterly 20 (4):365-384.

Colegrove, Kiyomi Sanchez-Suzuki, and Jennifer Keys Adair. 2014. "Countering Deficit Thinking: Agency, Capabilities, and the Early Learning Experiences of Children of Latina/o Immigrants." Contemporary Issues in Early Childhood 15 (2):122-135

Corsaro, William A. 2003. We're Friends Right? Inside Kids' Culture. Washington, DC: Joseph Henry Press.

Play $4(4): 488-504$.

Dewey, John. 1915/200o. The School and Society \& The Child and The Curriculum. Mineola, NY: Dover Publications.

Dyson, Anne Haas. 1993. Negotiating a Permeable Curriculum: On Literacy, Diversity, and The Interplay of Teacher's and Children's Worlds. Urbana, IL: National Council of Teachers of English.

2003. The Brothers and Sisters Learn to Write: Popular Literacies in Childhood and School Cultures. New York: Teachers College Press. 
2006. "On saying it right (write): "Fix-its" in the Foundations of Learning to Write." Research in the Teaching of English 41 (1):8-42.

Dyson, Anne Haas, and Celia Genishi. 2014. "Play as the Precursor for Literacy Development." In SAGE Handbook of Play and Learning in Early Childhood, edited by Liz Brooker, Mindy Blaise and Susan Edwards, 228-239. London: Sage.

Fernie, David, Samara Madrid, and Rebecca Kantor, eds. 2011. Educating Toddlers to Teachers: Learning to See and Influence the School and Peer Cultures of Classrooms. New York: Hampton Press.

Fleer, Marilyn. 2014. "The Demands and Motives Afforded through Digital Play in Early Childhood Activity Settings." Learning, Culture, and Social Interaction 3 (3):202-209. doi: http://dx.doi.org/10.1016/j.lcsi.2014.02.012.

Galbraith, Jeanne. 2011. "“Welcome to Our Team, Shark Boy”: Making Superhero Play Visible." In Educating Toddlers to Teachers: Learning to See and Influence the School and Peer Cultures of Classrooms, edited by David Fernie, Samara Madrid and Rebecca Kantor, 37-62. New York: Hampton Press.

Gee, James Paul. 1996. Social Linguistics and Literacies: Ideology in Discourses. London: RoutledgeFalmer.

Goffman, Erving. 1974. Frame Analysis: An Essay on the Organization of Experience. New York: Harper Row.

Göncü, Artin. 1999. "Children's and Researchers' Engagement in the World." In Children's Engagement in the World: Sociocultural Perspectives, edited by Artin Göncü, 3-22. Cambridge: Cambridge University Press.

Grace, Donna J., and Joseph Tobin. 1997. "Carnival in the Classroom: Elementary Students Making Videos." Making a Place for Pleasure in Early Childhood Education,159-187.

Grieshaber, Susan, and Felicity McArdle. 2010. The trouble with play. Maidenhead, Berkshire, UK: Open University Press.

Gregory, Eve, Susi Long, and Dinah Volk. Many Pathways to Literacy: Young Children Learning with Siblings, Grandparents, Peers, and Communities. Psychology Press, 2004 .

Hobbs, Renee. 2016. “Media Literacy.” In Oxford Research Encyclopedia of Communication. Oxford: Oxford University Press.

Hobbs, Renee, and Amy Jensen. 2009. "The Past, Present, and Future of Media Literacy 
Education." Journal of Media Literacy Education 1:1-11.

Holland, Dorothy, William Lachicotte, Debra Skinner, and Carole Cain. 1998. Identity and Agency in Cultural Worlds. Cambridge, MA: Harvard University Press.

Jenkins, Henry, Ravi Purushotma, Katherine Clinton, Alice J. Robison, and Margaret Weigel. 2006. Confronting the Challenges of Participatory Culture: Media Education for the 21st Century. Chicago: The John D. and Catherine T. MacArthur Foundation.

Jones, Liz, Maggie MacLure, Rachel Holmes, and Christina MacRae. 2012. "Children and Objects: Affection and Infection." Early Years 32 (1):49-6o.

Kamler, Barbara. 1999. "This Lovely Doll Who's Come to School: Morning Talk as Gendered Language Practice." In Constructing Gender and Difference: Critical Research Perspectives on Early Childhood, edited by Barbara Kamler. 191-214. Cresskill, NJ: Hampton Press.

Kontovourki, Stavroula, and Marjorie Siegel. 2009. "Discipline and Play with/in a Mandated Literacy Curriculum." Language Arts 87(1): 30-38.

Löfdahl, Annica. 2014. "Play and Peer Cultures." In SAGE Handbook of Play and Learning in Early Childhood, edited by Liz Brooker, Mindy Blaise and Susan Edwards, 342-353. London: Sage.

Marsh, Jackie. 2014. "Media, Popular Culture, and Play." In SAGE Handbook of Play and Learning in Early Childhood, edited by Liz Brooker, Mindy Blaise and Susan Edwards, 403-414. London: Sage.

Marsh, Jackie, and Elaine Millard (eds.). 20o6. Popular literacies, childhood, and schooling. New York: Routledge.

McDermott, Ray P. 1985. "Achieving School Failure: An Anthropological Approach to Illiteracy and Social Stratification." In Theoretical Models and Processes of Reading, edited by Harry Singer and Robert B. Ruddell, 558-594.

Medina, Carmen L., \& Karen E. Wohlwend. 2014. Literacy, Play, and Globalization: Critical and Cultural Performances in Children's Converging Imaginaries. New York: Routledge.

Mehan, Hugh. 1979. Learning Lessons: Social Organization in the Classroom. Cambridge, MA: Harvard University Press.

Moll, Luis C., Cathy Amanti, Deborah Neff, and Norma Gonzalez. 1992. "Funds of Knowledge for Teaching: Using a Qualitative Approach to Connect Homes and Classrooms." Theory Into Practice 31:132-141. 
Paley, Vivian Gussin. 2004. A Child's Work: The Importance of Fantasy Play. Chicago: University of Chicago Press.

Paris, Scott G. 2005. "Reinterpreting the Development of Reading Skills." Reading Research Quarterly 40(2): 184-202.

Pompe, Cathy. 1996. "'But They're Pink!" -- "Who Cares!": Popular Culture in the Primary Years." In Potent Fictions: Children's Literacy and the Challenge of Popular Culture, edited by Mary Hilton, 92-125. London: Routledge.

Pugh, Allison J. 2009. Longing and Belonging: Parents, Children, and Consumer Culture. Berkeley, CA: University of California Press.

Ray, Katie Wood, and Matt Glover. 2008. Already Ready: Nurturing Writers in Preschool and Kindergarten. Heinemann. Portsmouth, NH: Heinemann.

Roskos, Kathleen A., and James F. Christie. 2001. "Examining the Play-Literacy Interface: A Critical Review and Future Directions." Journal of Early Childhood Literacy 1 (1):59-89.

Scollon, Ron. 2001. Mediated Discourse: The Nexus of Practice. London: Routledge.

Scollon, Ron, and Suzanne Wong Scollon. 2004. Nexus Analysis: Discourse and the Emerging Internet. New York: Routledge.

Sefton-Green, Julian, Jackie Marsh, Ola Erstad, and Rosie Flewitt. 2016. Establishing a Research Agenda for the Digital Literacy Practices of Young Children: a White Paper for COST Action IS1410. Retrieved from http://digilitey.eu/wpcontent/uploads/2015/og/DigiLitEYWP.pdf

Seiter, Ellen. 1993. Sold Separately: Children and Parents in Consumer Culture. Piscataway, NJ: Rutgers University Press.

Sutton-Smith, Brian. 1997. The Ambiguity of Play. Cambridge, MA: Harvard University Press.

Thiel, Jaye Johnson. 2014. "Privileged Play: The Risky Business of Language in the Primary Classroom." Perspectives and Provocations 1.

Vasquez, Vivian Maria, and Carol Branigan Felderman. 2012. Technology and Critical Literacy in Early Childhood. New York: Routledge.

Vygotsky, Lev. 1935/1978. Mind in Society. Translated by Alexander Luria, Martin LopezMorillas and Michael Cole. Cambridge, MA: Harvard University Press. 
Wartella, Ellen , Courtney K. Blackwell, Alexis R. Lauricella, and Michael B. Robb. 2013. Technology in the Lives of Educators and Early Childhood Programs: 2012 Survey of Early Childhood Educators. Latrobe, PA: Fred Rogers Center for Early Learning and Children's Media.

Willett, Rebekah, Chris Richards, Jackie Marsh, Andrew Burn, and Julia C. Bishop. 2013. Children, Media and Playground Cultures: Ethnographic Studies of School Playtimes. London: Palgrave Macmillan.

Wohlwend, Karen E. 2013. Literacy Playshop: New Literacies, Popular Media, and Play in the Early Childhood Classroom. New York: Teachers College Press.

. 2012. “"Are You Guys Girls?': Boys, Identity Texts, and Disney Princess Play." Journal of Early Childhood Literacy, 12(3), 3-23.

. 2011. Playing Their Way into Literacies: Reading, Writing, and Belonging in the Early Childhood Classroom. NY: Teachers College Press.

. 2009a. "Damsels in Discourse: Girls Consuming and Producing Identity Texts through Disney Princess Play. "Reading Research Quarterly, 44(1), 57-83.

2009b. "Early Adopters: Playing New Literacies and Pretending New Technologies in Print-Centric Classrooms." Journal of Early Childhood Literacy, 9(2), 119-143. 2007. Friendship meeting or blocking circle? Identities in the laminated spaces of a playground conflict. Contemporary Issues in Early Childhood, $8(1), 73-88$

. 2015. "Case Study on Play, Space, and Literacy." In J. Marsh \& J. Larson, Making Literacy Real: Theories And Practices For Learning And Teaching (2nd ed., pp. 118-127). London: Sage. 